\title{
Identification of risk investment using the risk matrix on railway facilities
}

https://doi.org/10.1515/eng-2018-0057

Received April 23, 2018; accepted August 27, 2018

\begin{abstract}
The implementation of construction projects is fraught with many hazards that are difficult to determine at the stage of the tender procedure. Usually, the identification of these hazards rests with the contractors. In many cases this diagnosis is not used due to the lack of access to reliable data and easy-to-use computer programs supporting the risk analysis process.

In order to facilitate the analysis and risk assessment on Polish railway investments, the authors present a proposal for the assessment of potential hazards that may occur during the implementation of these investments with the use of their point assessment. The proposed method is an original attempt to apply a point assessment of risk factors, whose final result is ready investment risk assessment matrices at the design and execution stage of construction works. The basis for the development of matrices was questionnaire surveys involving a large group of experts with extensive professional experience. In addition, the project manager can set the partial weights of hazards separately for time and cost hazards depending on the assessment of the planned project. In order to quickly calculate the weights of individual risk factors for any defined time and cost of partial weights, the authors developed the proposed matrices in the form of a calculation sheet. The matrices can be used to assess potential hazards to future infrastructure investments.
\end{abstract}

Keywords: threat identification, risk, railway investments, planning of construction works

\footnotetext{
*Corresponding Author: Jan Kowalski: Warsaw University of Life Science - SGGW, Faculty of Civil and Environmental Engineering, Nowoursynowska 159, 02-776Warsaw, Poland, E-mail: jan_kowalski@sggw.pl

Mieczyslaw Polonski: Warsaw University of Life Science - SGGW, Faculty of Civil and Environmental Engineering, Nowoursynowska 159, 02-776Warsaw, Poland
}

\section{Introduction}

Risk management is a management method that focuses on identifying and controlling areas or events that can lead to unwanted changes [1]. According to this definition, the authors of the article perceive risk management from the perspective of the project manager. The authors do not write about the risks associated with insurance, security or other risk areas that go beyond the management of construction projects, but focus only on the risks arising from the specificity of railway investments in Poland.

Risk management is an integral part of project management and as such should be a part of any project management methodology, including construction projects. Unfortunately, currently as a result of very short deadlines for construction investments imposed by investors, risk management often goes to the background. In enterprises that are successful on a daily basis and failures are rare, risk management is marginalized in the hope that project managers will be able to cope with problems when they occur. Sadly, according to the authors' research so far [24] and information contained in many sources, [5-7] the problem is more complex. In the case of hazards identified during the implementation of railway investments (as in many other construction sectors) there is usually no time or secured reserve resources for preventive measures. To prevent this from happening, risk management at the investment planning stage should be one of the obligatory steps in preparing the documentation. One cannot allow risk management to be considered a "dark side" of the project, and the project manager as a forerunner and harbinger of all misfortunes. Realistic, transparent, welldeveloped and adapted to the situation sets of procedures and solutions are a long-term condition for the survival of any organization [1], including companies involved in planning and executing construction investments.

There are many tools (computer programs) on the construction market that allow to build schedules and manage risk. As Skorupka writes Skorupka [8], these are welldesigned graphically programs which offer a wide range of mathematical methods, however their disadvantages are the price and quite complicated service (e.g. the Risk 4.1 
for Project manual has 800 pages). The reason is that they are used only by large construction concerns. As Skorupka rightly notes [8], a well-designed risk analysis should be based on a reliable database, and none of these programs guarantees such. The authors of the article also share this opinion, and with the aim of a wider recognition of the problem, they gathered a database of identified hazards occurring during the implementation of Polish railway investments. These data became the foundation for the development of risk matrices, presented later in the article. These matrices, combined with a thorough analysis of contract documents, will enable efficient identification and assessment of potential hazards during planning of subsequent railway investments.

\section{Identification of risk factors}

The presented assessment of risk factors was developed on the basis of broader research on the implementation of railway investments.

These studies included the query of available foreign and domestic literature as well as the analysis of contract documentation for a large railway project implemented in Poland. During this research, the authors analyzed: a set of documents from the tender procedure (Specification of Essential Terms of the Contract, Description of the Object of the Contract, design concept, etc.), project documentation from the implementation stage (design concept, construction design, detailed design), decision on building permit (29 items), decisions on demolition permits (20 items), contract correspondence (over 12,000 letters), claims of parties to the contract (over 50 applications). The research was carried out in the years 2015 - 2016.

Based on the above analyzes, in 2017, the authors compiled the most important identified problems, which significantly impeded the implementation of railway investments. The list of hazards prepared in this way became the basis for carrying out surveys addressed to a selected group of experts. These were people who, on behalf of the Employer, Contractor, Designer or Contract Engineer as part of their professional duties, were responsible for the comprehensive management of railway contracts and had extensive professional experience in this area. A questionnaire was prepared, the content of which, as part of consultations and pilot studies, was agreed with selected experts. This questionnaire was sent to respondents electronically. It included closed and open questions regarding the identification of risk factors both at the design stage and the implementation of railway investments [9].
In the final result, 112 copies of correctly completed questionnaires in the scope of the design stage and 85 copies from the build stage were obtained. The data collected in this way was then subjected to statistical processing. The data were appropriately grouped into numerical sets and developed using the appropriate statistical models available in the IBM SPSS Statistics 23 package. It was used to carry out $\chi 2$ tests and a one-way analysis of variance in the intergroup scheme. Post-hoc tests were also performed to verify which specific events are rated as more or less problematic than others. During the statistical analysis, the classic level of $p<0.05$ was considered to be the statistical significance level.

After making the above analyzes and research, the authors received a set of reliable data on hazards that were identified nationwide (Tables 1 and 2).

The verification of risk factors in the scope of determining the validity of individual hazards from the design stage is presented in Table 1. M means the average rating of a given factor (on a scale of 0-10) calculated on the basis of all correctly provided answers. SD determines the standard deviation of this assessment, and thus indicates the compatibility of experts as to the possibility of occurrence of a given hazard. ZT determines the number of respondents who indicated that a given factor has a significant impact on the completion date of the investment, and the number of respondents who indicated that a given factor has a significant impact on the possibility of exceeding the planned cost.

The statistical analysis carried out showed that the obtained results are statistically significant: $F(14.17)=7.79$, $p<0,001, \eta^{2}=0.06$. Such a result allowed to perform the analysis by post-hoc Sidak test. The analysis made comparisons of each event with each, which allowed to determine the assessment of individual hazards.

Analogically, hazards from the build stage were presented in Table 2. The statistical calculations were done identically to those indicated in Table 1 . The obtained results were also statistically significant: $F(10.924)=8.27, p$ $<0.001, \chi^{2}=0.08$ (Table 2).

After gathering a reliable database on the assessment of potential hazards, the authors developed a risk matrix with a point assessment of individual hazards.

\section{Calculation of the risk factors weights}

Performing a quantitative risk analysis for future railway investments requires that individual hazards have a mea- 
Table 1: Identified hazards - design stage.

\begin{tabular}{|c|c|c|c|c|c|}
\hline No. & Descritipion of investigated hazards & M & $S D$ & ZT & ZK \\
\hline (1) & $(2)$ & (3) & (4) & (5) & (6) \\
\hline 1 & Procedural defects in preparation of tender documents & 5.90 & 3.18 & 94 & 94 \\
\hline 2 & $\begin{array}{l}\text { Improperly estimated deadline for the development of } \\
\text { project documentation by the Commissioning party }\end{array}$ & 5.00 & 3.75 & 74 & 58 \\
\hline 3 & $\begin{array}{l}\text { Too many external institutions involved in the investment } \\
\text { process }\end{array}$ & 4.35 & 2.87 & 82 & 55 \\
\hline 4 & $\begin{array}{l}\text { The necessity to make exceptions to the guidelines from } \\
\text { the tender stage }\end{array}$ & 4.68 & 2.76 & 81 & 78 \\
\hline 5 & $\begin{array}{l}\text { Errors in the conceptual design documentation from the } \\
\text { tender stage }\end{array}$ & 4.47 & 3.18 & 75 & 71 \\
\hline 6 & $\begin{array}{l}\text { Problems with obtaining current maps for project purposes } \\
\text { from rail geodesic centers }\end{array}$ & 6.48 & 3.28 & 91 & 78 \\
\hline 7 & $\begin{array}{l}\text { Problems with reconciliation of project documentation } \\
\text { with external Stakeholders }\end{array}$ & 5.36 & 2.86 & 88 & 66 \\
\hline 8 & $\begin{array}{l}\text { Problems with reconciliation of project documentation } \\
\text { with internal companies from the PKP group } \\
\text { Problems with reconciliation of project documentation }\end{array}$ & 4.60 & 2.85 & 77 & 58 \\
\hline 9 & $\begin{array}{l}\text { with the owners of technical infrastructure on the premises } \\
\text { of PKP }\end{array}$ & 4.34 & 2.73 & 73 & 64 \\
\hline 10 & $\begin{array}{l}\text { Long-term procedures for agreeing project documentation } \\
\text { within PKP PLK }\end{array}$ & 5.11 & 2.96 & 84 & 55 \\
\hline 11 & $\begin{array}{l}\text { Problems with the acceptance of project documentation by } \\
\text { the Contract Engineer } \\
\text { Did the Commissioning Party have a set of legal }\end{array}$ & 3.21 & 2.94 & 52 & 32 \\
\hline 12 & $\begin{array}{l}\text { documents regarding the area planned for the investment } \\
\text { within the deadline? }\end{array}$ & 4.46 & 3.10 & 75 & 54 \\
\hline 13 & $\begin{array}{l}\text { Was obtaining the decision on building permits delayed } \\
\text { due to the fault of the Commissioning Party? }\end{array}$ & 3.51 & 3.35 & 48 & 42 \\
\hline 14 & $\begin{array}{l}\text { Was the decision on building permits delayed due to the } \\
\text { Designer's fault? }\end{array}$ & 4.21 & 3.63 & 54 & 41 \\
\hline 15 & $\begin{array}{l}\text { Was the decision on building permits delayed due to the } \\
\text { fault of the external unit, e.g. additional agreements? }\end{array}$ & 5.03 & 3.62 & 71 & 67 \\
\hline
\end{tabular}

surable assessment of their significance. When calculating these values, the authors sought to include all the elements of expert assessment that were taken into account in the analyzed questionnaire, and therefore their validity (M), certainty of estimation (SD), and their impact on the time and cost of the planned investment. The point score was made on a scale of 0-10.

To determine the individual weights of each identified hazard, the authors made calculations as described below.

First, the data from tables 1 and 2 were normalized. The calculations were made on the basis of equations (1-3):
- Normalization of the average weight value for the nth event $\mathrm{M}_{z n}$ :

$$
M_{z n}=\frac{M_{n}-0}{(10-0)}
$$

where:

$M_{z n}$ - normalized value of the average rating for the nth hazard,

$M_{n}$ - the value of the average rating for a particular hazard, 0,10 - the grading scale used in the survey.

- Normalization of the number of hazards affecting the date of ZT

$$
Z T_{z n}=\frac{Z T n}{N}
$$

where:

$Z T_{z n}$ - normalized nth hazard affecting the deadline, 
Table 2: Identified hazards - build stage.

\begin{tabular}{|c|c|c|c|c|c|}
\hline No. & Descritipion of investigated hazards & $M$ & SD & $\mathbf{Z T}$ & ZK \\
\hline (1) & (2) & (3) & (4) & $(5)$ & $(6)$ \\
\hline 1 & $\begin{array}{l}\text { Errors in the preparation of tender documents (SIWZ, OPZ, } \\
\mathrm{PFU).}\end{array}$ & 5.40 & 3.40 & 74 & 72 \\
\hline 2 & $\begin{array}{l}\text { Improperly estimated time of completion of the investment by } \\
\text { the Employer. }\end{array}$ & 4.91 & 3.46 & 62 & 59 \\
\hline 3 & $\begin{array}{l}\text { Too many external institutions involved in the investment } \\
\text { process. }\end{array}$ & 3.80 & 3.15 & 52 & 40 \\
\hline 4 & $\begin{array}{l}\text { Terms of the contract not adapted to the contract specificity } \\
\text { (FIDIC Red, FIDIC Yellow, others). }\end{array}$ & 5.36 & 3.31 & 59 & 54 \\
\hline 5 & $\begin{array}{l}\text { th costs by the Contractor (financial } \\
\text { r). }\end{array}$ & 5.28 & 3.20 & 46 & 44 \\
\hline 6 & $\begin{array}{l}\text { Difficulties in the preparation, in terms of formal, legal and } \\
\text { technical areas for investment. }\end{array}$ & 5.36 & 3.07 & 61 & 50 \\
\hline 7 & $\begin{array}{l}\text { Internal regulations of PKP PLK SA not coordinated with the } \\
\text { provisions of contracts. }\end{array}$ & 2.93 & 3.21 & 45 & 31 \\
\hline 8 & Errors in project documentation & 5.76 & 3.54 & 62 & 59 \\
\hline 9 & $\begin{array}{l}\text { Badly estimated investment costs by the Contractor (financial } \\
\text { problems of the Contractor). }\end{array}$ & 6.00 & 3.57 & 60 & 65 \\
\hline 10 & Awarding shorter track closures to the contractor. & 5.74 & 3.69 & 62 & 61 \\
\hline 11 & $\begin{array}{l}\text { Problems with outdated geodetic materials (numerous } \\
\text { collisions with non-inventory of underground infrastructure). }\end{array}$ & 6.69 & 2.94 & 63 & 69 \\
\hline
\end{tabular}

$Z_{T n}$ - the number of assessments indicating that a given hazard may have an impact on the time of investment implementation,

$N$ - number of surveys for a given investment stage (design stage 112 copies, build stage 85 copies).

- Standardization of the number of hazards affecting the increase of ZK costs:

$$
Z K_{z n}=\frac{Z K n}{N}
$$

where:

$Z K_{z n}$ - normalized $\mathrm{n}$-th hazard affecting the cost of implementation,

$Z_{K n}{ }^{-}$- number of assessments indicating that a given hazard may affect the cost of investment implementation,

$N$ - number of surveys from a given investment stage.

In the second step, individual normalized values were aggregated. The $\mathrm{M}_{z n}$ assessment was additionally reinforced with the standard deviation evaluation, obtaining the $\mathrm{M}_{k n}$ value. It resulted from the fact that the smaller the standard deviation for a given hazard, the greater the compat- ibility of experts as to the possibility of its occurrence:

$$
M_{k n}=M_{z n}\left[1+\frac{M_{z n}\left(\frac{S D_{\max }-S D_{n}}{S D_{\max }-S D_{\min }}\right)}{6}\right]
$$

where:

$M_{k n}$ - enhanced $M_{z}$ value due to standard deviation $S D_{n}$, $S D_{n}$ - standard deviation of hazard $\mathrm{n}$,

$S D_{\max }, S D_{\min }$-maximum and minimum standard deviation value for all hazards from a given investment stage, $M_{z n}$ - normalized value of the average rating for the nth hazard.

The value of the final, non-dominated weight of each Wn hazard was calculated according to the following formula:

$$
W_{n}=M_{k n}+\left(Z T_{z n} \cdot K_{T}\right)+\left(Z K_{z n} \cdot K_{K}\right)
$$

when

$$
K_{T}+K_{K}=1
$$

where:

$K_{T}$ and $K_{K}$ - common to all hazards in a given matrix partial weight of hazards: time of investment $\left(K_{T}\right)$ and investment cost $\left(K_{K}\right)$. 
Table 3: Risk matrix with values of normalized weights and their ranking position for $K T=K K=0.5-$ design stage.

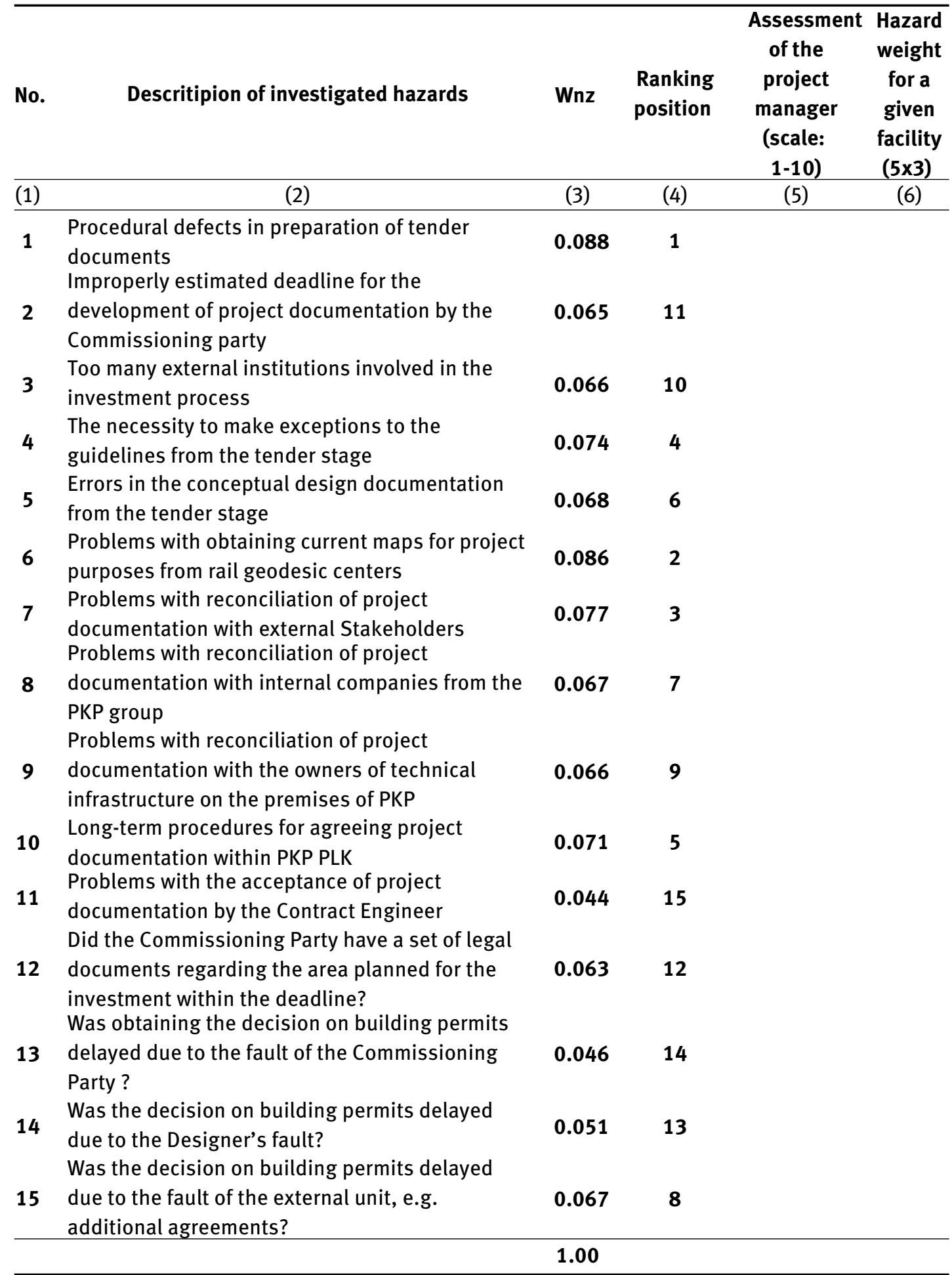

The final normalized weight value of individual hazards was calculated as:

$$
W_{n z}=\frac{W_{n}}{\sum_{i}^{N} W_{n}} \text { and } \sum_{1}^{N} W_{n z}=1
$$

As can be seen from formula 5, in the final formula determining the importance of individual hazards, common partial weights of all hazards can be applied separately for time and cost hazards. The decision on the value of these 
Table 4: Risk matrix with values of normalized weights and their ranking position for $K_{T}=K_{K}=0.5$-build stage

\begin{tabular}{|c|c|c|c|c|c|}
\hline No. & Descritipion of investigated hazards & Wnz & $\begin{array}{l}\text { Ranking } \\
\text { position }\end{array}$ & $\begin{array}{l}\text { Assessment } \\
\text { of the } \\
\text { project } \\
\text { manager } \\
\text { (scale: } \\
1-10)\end{array}$ & $\begin{array}{c}\text { Hazard } \\
\text { weight } \\
\text { for a } \\
\text { given } \\
\text { facility } \\
(5 \times 3)\end{array}$ \\
\hline (1) & (2) & (3) & (4) & (5) & (6) \\
\hline 1 & $\begin{array}{l}\text { Errors in the preparation of tender documents } \\
\text { (SIWZ, OPZ, PFU). }\end{array}$ & 0.086 & 7 & & \\
\hline 2 & $\begin{array}{l}\text { Improperly estimated time of completion of the } \\
\text { investment by the Employer. }\end{array}$ & 0.074 & 9 & & \\
\hline 3 & $\begin{array}{l}\text { Too many external institutions involved in the } \\
\text { investment process. }\end{array}$ & 0.056 & 11 & & \\
\hline 4 & $\begin{array}{l}\text { Terms of the contract not adapted to the contract } \\
\text { specificity (FIDIC Red, FIDIC Yellow, others). }\end{array}$ & 0.077 & 8 & & \\
\hline 5 & $\begin{array}{l}\text { Badly estimated investment costs by the } \\
\text { Contractor (financial problems of the Contractor). }\end{array}$ & 0.091 & 6 & & \\
\hline 6 & $\begin{array}{l}\text { Difficulties in the preparation, in terms of formal, } \\
\text { legal and technical areas for investment. }\end{array}$ & 0.103 & 5 & & \\
\hline 7 & $\begin{array}{l}\text { Internal regulations of PKP PLK SA not } \\
\text { coordinated with the provisions of contracts. }\end{array}$ & 0.063 & 10 & & \\
\hline 8 & Errors in project documentation & 0.107 & 3 & & \\
\hline 9 & $\begin{array}{l}\text { Badly estimated investment costs by the } \\
\text { Contractor (financial problems of the Contractor). }\end{array}$ & 0.110 & 2 & & \\
\hline 10 & Awarding shorter track closures to the contractor. & 0.106 & 4 & & \\
\hline 11 & $\begin{array}{l}\text { Problems with outdated geodetic materials } \\
\text { (numerous collisions with non-inventory of } \\
\text { underground infrastructure). }\end{array}$ & 0.127 & 1 & & \\
\hline & & 1.00 & & & \\
\hline
\end{tabular}

partial weights was left to the manager of the planned investment, depending on the situation of the project. Naturally, these weights can be the same and then $K_{T}=K_{K}=0,5$ or, for example, extreme, i.e. $K_{T}=0 ; K_{K}=1$ or vice versa.

\section{Application of the proposed risk matrix}

In order to use the developed risk matrices with the possibility to quickly calculate the weights of individual risk factors for arbitrarily defined time and cost partial weights $\left(K_{T}\right.$ and $\left.K_{K}\right)$, the authors developed proposed matrices in the form of a calculation sheet. After declaring the values of these weights, the sheet will calculate the final normalized value of the weights of individual $W n z$ hazards and their current ranking position. The matrices constructed in this way are a ready tool supporting risk assessment on future railway investments. Below are exemplary severity scales for the design stage (Table 3) and implementation (Table 4) with weights $K_{T}=K_{K}=0.5$.

The step necessary to use the proposed matrices must be a detailed recognition of the conditions for the planned investment. It should cover all aspects that may affect the implementation of the future investment, hence both technical and legal, financial, organizational or technological. Correct recognition of these conditions will facilitate the query of all available documentation, and its results will allow the analysis team to determine the necessary, own assessment of hazards contained in the risk matrix in relation to a specific, planned investment. It is essential that these activities be performed as a team. This will minimize the impact of subjective assessments of individual experts, which is considered a of point assessment of risk. 
Only the combination of these two elements, i.e. the general assessment of individual hazards contained in the matrix and the subjective assessment taking into account the conditions for the planned investment, will allow the precise determination of risk elements of the analyzed investment and prepare adequate preventive measures in the form of properly located and calculated time buffers and/or reserve financial resources [10, 11].

The methodology of calculating such defined risk assessments and their impact on the project's time and financial schedule will be the subject of further work of the authors. In subsequent publications, computational examples will be presented using the proposed risk matrix.

\section{Summary and conclusions}

The authors' research carried out for several years and literature data clearly indicate that the implementation of railway investments is subject to considerable risks, both at the stage of design works and during construction works. The article proposes a ready-made tool for forecasting the impact of identified hazards on planned Polish railway investments. The tool has the form of a risk matrix and is developed in the form of a spreadsheet, separately for the design and execution stages of the works. Because the proposed matrices were developed on the basis of reliable results of a nationwide survey, they should be considered valuable, both for scientific and practical purposes.

Making matrices available in the form of spreadsheets will allow managers of railway projects to easily make the necessary calculations, and focus the main attention on the analysis of project implementation conditions and assessment of the occurrence of potential hazards during planned works. The risk factors included in the matrices include risks that, in the opinion of a wide range of experts, may disrupt the planned works, and the calculated weights of these factors and their ranking positions at a given time and cost will help assess their impact on the future project.

Nevertheless, it should be remembered that the proposed point assessment of risk, although seemingly very simple, requires an in-depth analysis of the environment of the planned investments and brings many pitfalls. One of them is the subjectivism of the assessment, especially in those areas where the assessments are based on a qualitative analysis. That is why it is so important that individual hazards are assessed by a team of competent project managers who are able to assess the impact on the planned in- vestment of many interrelated technical, financial and legal factors, etc.

\section{References}

[1] Pritchard C.L., Risk Management Concepts and Guidance, (P. Dabrowski, Tran.), 2002, Warszawa, WIG - PRESS

[2] Polonski M., Kowalski J., Problems at the stage to agree project documentation for railway contracts using FIDIC Conditions of Contract. Materiały Budowlane, no 6, 2016, 162-163, (in Polish)

[3] Kowalski J., Polonski M., Indentification of hazards related with the stakeholders group during railway investments in Poland, ACTA Architektura, 16 (4), 2017, 83-92, (in Polish)

[4] Polonski M., Kowalski J., The identification of hazards concerning the character of construction works on railway sites in Polnad, Technical transactions, no 5, 2017, 47-55.

[5] Lendo Siwicka M., Pawluk K., Polonski M., Goszczynska, A., Management of the construction project according to FIDIC procedures in contractors view, Materiały Budowlane, no 6, 2016, 154-155, (in Polish)

[6] Latawiec, T. Rynek infrastruktury. http://www.rynek. infrastruktury.pl/wiadomosci/zmiana-modelu-realizacjiinwestycji-kolejowych-potrzebna-od-zaraz-53472.ftml

[7] Bizon-Gorecka J., Gorecki J., Risk of construction investment project in different project delivery systems, Studies \& Proceedings of Polish Association for Knowledge Management, 2015, No. 74

[8] Skorupka D., Quantification and allocation of risk factors in network construction schedules. Zeszyty Naukowe / Wyższa Szkoła Oficerska Wojsk Lądowych im. gen. T. Kościuszki, 2018, 145-159, (in Polish)

[9] Kowalski J., Polonski M., Risk factors for delays in rail investments implemented in the Design \& Build contracts, Archives of Civil Engineering

[10] Polonski M., Application Of The Work Breakdown Structure In Determining Cost Buffers In Construction Schedules. Arch Civ Eng, 2015, https://www.degruyter.com/view/j/ace.2015.61. issue-1/ace-2015-0010/ace-2015-0010.xml

[11] Polonski M., Pruszynski, K., Impact of Baseline Terms on the Course of Critical Paths and Time Buffers in the Modified Goldratt's Method, 2013, http://www.degruyter.com/view/j/ace. 2013.59.issue-3/ace-2013-0017/ace-2013-0017.xml 